\title{
Understanding consumer preferences and demography in order to reduce the domestic trade in wild-caught birds
}

\author{
Zuzana Burivalova ${ }^{\mathrm{a}, \mathrm{b}, *}$, Tien Ming Lee ${ }^{\mathrm{a}}$, Fangyuan Hua ${ }^{\mathrm{a}}$, Janice S.H. Lee ${ }^{\mathrm{a}, \mathrm{c}}$, \\ Dewi M. Prawiradilaga ${ }^{\mathrm{d}}$, David S. Wilcove ${ }^{\mathrm{a}, \mathrm{b}}$ \\ a Woodrow Wilson School of Public and International Affairs, Princeton University, USA \\ ${ }^{b}$ Department of Ecology and Evolutionary Biology, Princeton University, USA \\ c Asian School of the Environment, Nanyang Technological University, Singapore \\ d Research Center for Biology, Indonesian Institute of Science, Indonesia
}

\section{A R T I C L E I N F O}

\section{Article history:}

Received 2 December 2016

Received in revised form 23 February 2017

Accepted 2 March 2017

Available online 21 March 2017

\section{Keywords:}

Wildlife trade

Captive-bred alternative

Bird market

Pet birds

Song competition

Indonesia

Hunting

Market-based conservation intervention

\begin{abstract}
A B S T R A C T
The wildlife trade is now one of the greatest threats to biodiversity, and birds are among the most commonly traded groups worldwide. The demand for pet birds is especially high in Indonesia, a country with many exploited, imperiled bird species. Finding solutions to the threat that trade poses for birds, and wildlife in general, requires an understanding of its socioeconomic dimensions. We examined consumer demography and preferences of 762 bird owners in Medan, Sumatra, focusing on the differences among owners of birds taken from the wild versus birds bred in captivity. We found that the vast majority of bird owners have at least one wildcaught bird. However, wild-caught bird ownership is not uniformly distributed across Medan; rather, there are distinct hotspots with high proportions of people with wild-caught birds. The main reasons for owning wildcaught birds are lack of access to and the high cost of captive-bred birds, and a perception that captive-bred birds do not sing as well as wild-caught ones. We conclude that captive-breeding programs could reduce the pressure on wild populations, especially if suppliers are able to produce relatively cheap captive-bred birds. However, the perceived poorer song quality of captive-bred individuals might be a problem for the captive breeding of some species, notably the White-rumped Shama, Copsychus malabaricus. Since many owners of this species compete in bird song competitions, establishing competition categories specifically for captive-bred shamas could promote captive-bred bird ownership. Tackling the problem of the wild bird trade in Indonesia and elsewhere will require consideration of both the economic and the social factors that underlie pet ownership.
\end{abstract}

(c) 2017 Elsevier Ltd. All rights reserved.

\section{Introduction}

Wildlife trade is one of the greatest threats to biodiversity, particularly in Africa, Asia, and South America (Robinson et al., 1999; Alves et al., 2013; Challender et al., 2015a). Animals and plants are traded live as pets and collectors' items, or dead for medicine, ornaments, and trophies (Oldfield, 2003). Birds are one of the most commonly traded taxonomic groups worldwide, with 408 Red-Listed species classified as threatened at least in part by trade (Regueira and Bernard, 2012; Alves et al., 2013; Bush et al., 2014). Limiting the threat that trade poses to wildlife requires a rigorous understanding of the ecology of the traded species (e.g. the degree to which populations are in decline due to trade), as well as the economic (e.g. the sales volume and price

\footnotetext{
* Corresponding author at: Woodrow Wilson School of Public and International Affairs, Princeton University, USA.

E-mail address: zuzanab@princeton.edu (Z. Burivalova).
}

of the particular taxon traded, market mechanisms, the role of the wildlife trade in people's livelihoods) and social aspects of the wildlife trade (e.g., motivations for owning animals) (Regueira and Bernard, 2012; Phelps et al., 2014; Challender et al., 2015b; Harris et al., 2015). Even though wildlife trade has received increased attention from researchers and conservationists in recent years, its socioeconomic aspects remain poorly understood. Moreover, most of that attention has focused on a handful of charismatic species, such as elephants (Loxodonta spp.) and tigers (Panthera tigris), leaving the vast majority of exploited species understudied.

Across Southeast Asia, birds are heavily targeted for the pet trade, and Indonesia represents an important and suitable study system to understand the socioeconomic factors underlying that trade. An astounding $22 \%$ of Indonesia's households are estimated to keep birds as pets, and as many as $60 \%$ of bird-owning households are believed to have wild-caught birds (Jepson and Ladle, 2005). Bird song competitions are a popular activity, and, indeed, substantial prize money can be 
won with certain species (Jepson et al., 2011). Unsurprisingly, trapping is one of the major threats to a number of Indonesian bird species, further exacerbating the threat posed by habitat loss (Shepherd et al., 2004; Eaton et al., 2015; Harris et al., 2015, 2016). Several bird species have already been identified as being imperiled due to their popularity in the pet bird market, including Pycnonotus zeylanicus (Straw-headed Bulbul) and Garrulax bicolor (Sumatran Laughingthrush) (Harris et al., 2015). Some have even been driven to the brink of extinction, including Leucopsar rothschildi (Bali Myna) and Cacatua sulphurea (Yellow-crested Cockatoo) (Eaton et al., 2015; Harris et al., 2015). Wildlife trade thus poses a grave threat to Indonesia's avifauna, and it is therefore crucial to understand its socioeconomic aspects.

Here we aim to understand the socioeconomic factors underlying the pet bird trade in Medan, a major city on the island of Sumatra. This part of Indonesia includes some of the most important bird trade centers and has rapidly disappearing tropical forests harboring numerous endemic birds, including many traded species. Substantial conservation gains could likely be achieved if the bird trade were better understood in Sumatra. We focus particularly on the possibility of substituting wild-caught birds with captive-bred equivalents (Jepson and Ladle, 2005; Dutton et al., 2011; Williams et al., 2014; Phelps and Webb, 2015; Robinson et al., 2015). For such a conservation intervention to be both effective and enduring, a thorough ecological, economic, and social evidence base of the wildlife trade system has to be built up. We argue that, currently, the social dimension of the bird trade is the least well-understood part of the issue. For instance, detailed demographic profiles of bird owners are lacking, which largely prevents demographically targeted social marketing and implementation of conservation interventions (Jepson and Ladle, 2005).

Through structured interviews with bird owners, we: (1) quantify the frequency with which different bird species are owned by people in Medan, distinguishing between captive-bred and wild-caught individuals of each species; (2) establish demographic profiles of bird owners in Medan, Sumatra, and test whether there are any demographic differences between owners of wild-caught birds and captive-bred birds; (3) evaluate the reasons why owners might prefer wild-caught or captive-bred birds as pets; and (4) by carrying out a preliminary playback experiment and further interviews, explore these reasons further in the case of Copsychus malabaricus (White-rumped Shama), one of the most coveted bird species in Southeast Asia, which is both bred in captivity and captured in the wild.

\section{Methods}

\subsection{Study design}

We conducted structured household interviews of pet bird owners in Medan, Indonesia to understand the socioeconomic factors underlying their bird-keeping behavior. We carried out our research in two phases: Phase 1 (August 2014) involved detailed interviews with randomly selected bird owners. Informed by our findings from Phase 1, in Phase 2 (August 2015) we focused on owners of wild-caught $C$. malabaricus. Phase 2 entailed shorter interviews and a preliminary playback experiment to gauge the ability of bird owners to distinguish between the songs of wild-caught versus captive-bred individuals of $C$. malabaricus.

\subsubsection{Phase 1 interviews}

We collected data through structured household interviews with 762 bird owners in Medan in August 2014. Six trained local Indonesian interviewers randomly sampled interviewees in 10 districts of Medan. In each district, we established a target number of interviews to be carried out in proportion to the population size of that district, according to the 2010 Indonesian census (22-107 interviews per district). Within each district, we selected random sub-districts to which the interviewers traveled. Using a table of random 5-digit numbers, interviewers would stop at the $n$th intersection, where $n$ was the first digit of the first 5-digit number, alternating between left and right turns at each intersection. If this process led to an area with houses, the interviewers would sweep through the area systematically, looking for potential interviewees in the first 10 houses they encountered. The interviewers did not complete $>5$ interviews within a given sampling area. Once the sampling area was either fully swept, or 5 interviews were carried out, the interviewers used the next random number to get to the next sampling area.

The questions that the interviewers asked fell into three categories, reflecting our three research goals (see questionnaire in Supporting Information). The first set of questions focused on which species of birds the interviewees owned (at the time of the study and in the past), how many of each, and whether each bird was captive-bred or wildcaught. The interviewees were provided with pictures of common pet bird species to help them identify the bird species they owned. The second set of questions was designed to obtain basic demographic information from the interviewees, including age, self-reported socio-economic status, education, ethnicity, and religion. The third set of questions asked about reasons for owning or not owning captive-bred birds, as well as the interviewee's self-reported access to captive-bred birds. We cross-checked on a $10 \%$ structured subset of the original sample that interviews had been carried out by having an independent interviewer re-contact the interviewees; confirming that interviews had been indeed carried out in all cases.

\subsubsection{Phase 2 interviews}

In the second phase, we focused on 307 owners of wild-caught $C$. malabaricus. We chose this species for a case study based on our findings from Phase 1: this species is extremely popular and highly valued in bird song competitions. Additionally, its wild populations are declining due to trade (Harris et al., 2016), and anecdotal evidence suggests that captive breeding of this species is increasing in some parts of Indonesia, including Jakarta (T.M.L. personal observations). This set of 307 owners included both owners previously interviewed in Phase 1 (44 owners), and new interviewees (263 owners), whom we recruited through contacts and visits to bird song competitions. The interview component of Phase 2 consisted of the same questions we asked in Phase 1 related to the demography of bird owners, but it differed in the questions about reasons for not owning a captive-bred bird in that these questions referred specifically to C. malabaricus (see questionnaire in Supporting Information).

Answers from each interview in both Phases 1 and 2 were recorded on paper by one of the interviewers, and later entered into a database and translated from Bahasa Indonesia to English. Typically, two interviewers worked together as a team, and we aimed for each team to have one female interviewer, so as to not introduce any bias that the interviewer's gender might have on responses (Huddy et al., 1997; Flores-Macias and Chappell, 2008; Davis et al., 2010). We minimized data entry errors by employing a second assistant who checked all the data entered. The interview questions were not directly related to the interviewees' potential illegal behavior (e.g., owning a protected bird species), therefore we do not expect the results to be skewed toward positive responses. The study protocol was reviewed and approved by the Princeton University Institutional Review Board (permit number 6723 and 6724).

\subsubsection{Playback experiment}

Results from Phase 2 interviews suggested that many bird owners believe that the song of wild-caught $C$. malabaricus is superior to the song of captive-bred individuals, and that this perception is an important reason for owners to prefer wild-caught individuals (see Results). If this belief is not consistent with owners' actual preferences and abilities to distinguish between the songs of wild-caught and captive-bred $C$. malabaricus, then a potential conservation intervention to reduce trapping pressure on wild populations of $C$. malabaricus might include 
demonstrating to owners that they could not actually distinguish between wild-caught and captive-bred birds. This, in turn, could influence bird owners' behavior toward purchasing captive-bred individuals instead of wild-caught ones, and in time relieve the pressure on the wild populations of this species. We thus investigated whether bird owners did, in fact, prefer the song of a wild-caught $C$. malabaricus over that of a captive-bred one, by conducting a preliminary playback experiment involving a blind test of song preferences.

The playback experiment proceeded as follows: Randomly selected interviewees ( $n=159$, hereafter referred to as participants) in Phase 2 were asked to listen to two song recordings, one sung by a prize-winning wild-caught $C$. malabaricus (named "Happy Birthday") and one sung by a prize-winning captive-bred $C$. malabaricus (named "Pelor Mas"). Both birds had won approximately 1500 USD of prize money each, and were worth around 30,000 USD each. Both recordings had similar background noises and were recorded in a captive environment. Participants were informed that one is wild-caught and one is captivebred, but they were not told which was which. The song of each bird was played as a trimmed, high-quality 60 s recording, which participants listened to on an mp3 player with headphones (same model was used for all participants). No sound filtering or other editing was carried out. We obtained the song of Pelor Mas by recording the bird in the house of its owner; the song of "Happy Birthday" was taken from www.youtube.com at the request of its owner.

After listening to both recordings, each participant was asked to rate both songs on a scale of 1 to 5 , where $1=$ below average, $2=$ slightly below average, 3 = average, $4=$ slightly above average, $5=$ above average. The participants were also asked to state which song they thought was sung by the wild-caught bird. We emphasize that because we had access to recordings of only one captive-bred song champion and one wild-caught song champion, the results of this experiment must be considered preliminary.

\subsection{Statistical analysis}

\subsubsection{Species owned}

We summarized the number of individuals of each species owned, and ranked species by how commonly owned they were within our sample population of bird owners from Phase 1 . We considered that a given species occurs both as captive-bred and wild-caught within our sample population of owners when birds were present in both categories with at least $10 \%$ of the total number of individuals falling into the minority category. This is based on our assumption of a $10 \%$ error that owners might wrongly report a bird to be wild-caught or captive-bred.

\subsubsection{Demography}

To analyze the demographic profile of owners of wild-caught and captive-bred birds from Phase 1, we carried out a binomial logistic regression, with the following explanatory variables: age, district, ethnicity, religion, education, self-reported socio-economic status. We used these variables to explain both whether an owner had any captivebred birds, and whether an owner had any wild-caught birds (note that these two variables are asymmetrical, as one owner can have both wild-caught and captive-bred birds). We used the informationtheoretic approach for statistical inference, using the Akaike Information Criterion adjusted for small sample size (AICc; Akaike, 1973; Burnham and Anderson, 1998) to select the best model out of our set of candidate models (i.e. the model with the lowest AICc). The set of candidate models included all possible combinations of the explanatory variables (thus we assessed a total of $2^{n}=64$ models, plus a null model which had no variables). We did not consider interactions.

\subsubsection{Owners' preference}

We present the reasons people gave for owning wild-caught rather than captive-bred birds in two stages. First, we summarize the reasons owners gave in Phase 1 for owning a captive-bred bird in general if they did own one (any species), or the reasons for not owning a captive-bred bird if they did not own any. Second, we summarized the reasons owners of wild-caught $C$. malabaricus gave specifically for not owning a captive-bred C. malabaricus during the Phase 2 interview. To find out whether self-reported access is related to exclusive captivebred bird ownership, we carried out a logistic regression with self-reported access as an explanatory variable. We added the agreement scores for all questions relating to self-reported access and then standardized the total score to a scale from 0 to 1 .

\subsubsection{Playback experiment}

We calculated the probability of obtaining the total number of correct guesses as to whether a given recording was of a wild-caught or captive-bred C. malabaricus if owners were guessing at random (i.e. a Bernoulli trial) as

$f(x)=\left(\begin{array}{l}n \\ x\end{array}\right) p^{x}(1-p)^{(n-x)}$

where $x$ is the total number of successful guesses (see Results), $n$ is the number of owners (159), and $p$ is the probability of guessing correctly $(0.5$, since the participants were informed that exactly one recording is by a wild-caught bird). Our null hypothesis was that owners are not able to tell the difference between the two songs and are guessing at random, which we would reject if $f(x)<0.05$. We used an analysis of variance to see whether there was a significant difference in the rankings of the songs sung by wild-caught and captive-bred C. malabaricus. Our null hypothesis was that there is no difference between the ranking of the two songs.

\section{Results}

\subsection{Species owned}

In total, the 762 interviewees reported that they owned 2856 individual birds (between 3 and 4 birds per owner) belonging to 69 species. The 15 most popular species accounted for $90 \%$ of all birds owned, with Geopelia striata (Zebra Dove), Agapornis sp. (lovebird sp.), and Copsychus saularis (Oriental Magpie Robin) being the three most commonly owned species (Table 1). Captive-bred birds accounted for 39\% of all birds owned, with the vast majority of captive birds (75\%) belonging to three species that did not occur as a wild-caught variety in our sample population, namely Agapornis sp. (lovebird sp.), Serinus canaria (Canary), and Melopsittacus undulatus (Budgerigar). Fourteen species occurred as both wild-caught and captive-bred varieties, most commonly G. striata, C. saularis, Acridotheres tristis (Common Myna), and C. malabaricus (Table 1). $84 \%$ of the owners had at least one wild-caught bird, and $57 \%$ had only wild-caught birds. $43 \%$ had at least one captive-bred bird, and $16 \%$ had captive-bred birds only.

\subsection{Demography}

The owners interviewed were between 18 and 82 years old. The average age was 40 . Most owners (59\%) self-identified as being of Javanese ethnicity; the only other major ethnicity was Batak (17\%). The vast majority of interviewees reported their religion to be Islam (85\%). Most owners (70\%) had completed secondary education, 19\% had only basic education, and the remaining $11 \%$ had higher, university-level education. Two thirds of owners (66\%) reported their perceived (self-reported) socio-economic status as average, $17 \%$ placed themselves below average, and $17 \%$ above average.

The most parsimonious model of demographic differences between owners who had at least one captive-bred bird and those who had only wild-caught birds showed that district and self-reported socio-economic status were the most important variables (Table 2). This model showed that three of the ten districts (Baru, Tutungan, Sunggal) had 
Table 1

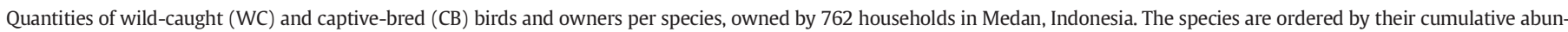

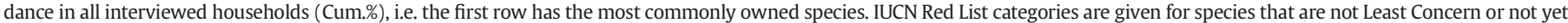
evaluated: NT = Near Threatened, VU = Vulnerable; EN = Endangered; CR = Critically Endangered.

\begin{tabular}{|c|c|c|c|c|c|c|c|}
\hline Species name & CB birds & WC birds & Total birds & Cum. \% & Owners of $\mathrm{CB}$ & Owners of WC & Total owners \\
\hline Geopelia striata (Zebra Dove) ${ }^{\mathrm{d}}$ & 64 & 430 & 494 & 17.3 & 33 & 227 & 260 \\
\hline Agapornis sp. (lovebird) & 402 & 0 & 402 & 31.4 & 139 & 0 & 139 \\
\hline Copsychus saularis (Oriental Magpie Robin) ${ }^{\mathrm{b}, \mathrm{c}, \mathrm{d}}$ & 44 & 277 & 321 & 42.6 & 34 & 206 & 240 \\
\hline Serinus canaria (Canary) & 285 & 0 & 285 & 52.6 & 104 & 0 & 104 \\
\hline Acridotheres tristis (Common Myna) ${ }^{\mathrm{d}}$ & 52 & 190 & 242 & 61.1 & 42 & 134 & 176 \\
\hline Copsychus malabaricus (White-rumped Shama) ) $^{\mathrm{a}, \mathrm{c}, \mathrm{d}}$ & 21 & 164 & 185 & 67.5 & 15 & 122 & 137 \\
\hline Melopsittacus undulatus (Budgerigar) & 156 & 0 & 156 & 73 & 63 & 0 & 63 \\
\hline Pycnonotus aurigaster (Sooty-headed Bulbul) & 7 & 122 & 129 & 77.5 & 6 & 100 & 106 \\
\hline Chloropsis sonnerati (Greater Green Leafbird VU) $)^{\mathrm{b}, \mathrm{c}, \mathrm{d}}$ & 14 & 105 & 119 & 81.7 & 13 & 91 & 104 \\
\hline Prinia familiaris (Bar-winged Prinia) & 4 & 59 & 63 & 83.9 & 4 & 46 & 50 \\
\hline Acridotheres javanicus (Javan Myna VU) ${ }^{\mathrm{b}}$ & 4 & 48 & 52 & 85.7 & 4 & 42 & 46 \\
\hline Alophoixus bres (Grey-cheeked Bulbul) ${ }^{\mathrm{b}}$ & 2 & 37 & 39 & 87.1 & 2 & 33 & 35 \\
\hline Columbidae sp. (pigeon) ${ }^{\mathrm{d}}$ & 18 & 13 & 31 & 88.2 & 6 & 5 & 11 \\
\hline Ploceus manyar (Streaked Weaver) & 2 & 26 & 28 & 89.1 & 1 & 19 & 20 \\
\hline Spilopelia chinensis (Spotted Dove) ${ }^{\mathrm{d}}$ & 6 & 19 & 25 & 90 & 4 & 16 & 20 \\
\hline Pycnonotus goiavier (Yellow-vented Bulbul) ${ }^{\mathrm{d}}$ & 3 & 21 & 24 & 90.9 & 2 & 18 & 20 \\
\hline Parus major (Great Tit) ${ }^{\mathrm{d}}$ & 2 & 17 & 19 & 91.5 & 2 & 14 & 16 \\
\hline Lonchura oryzivora (Java Sparrow VU) ${ }^{\mathrm{a}}$ & 0 & 19 & 19 & 92.2 & 0 & 16 & 16 \\
\hline Pycnonotus melanicterus (Black-capped Bulbul) ${ }^{\mathrm{b}}$ & 1 & 16 & 17 & 92.8 & 1 & 15 & 16 \\
\hline Chloropsis cochinchinensis (Blue-winged Leafbird NT) & 1 & 15 & 16 & 93.3 & 1 & 12 & 13 \\
\hline Gracula religiosa (Hill Myna) ${ }^{c}$ & 1 & 15 & 16 & 93.9 & 1 & 15 & 16 \\
\hline Lanius schach (Long-tailed Shrike) ${ }^{\mathrm{b}}$ & 1 & 14 & 15 & 94.4 & 1 & 13 & 14 \\
\hline Leiothrix argentauris (Silver-eared Mesia) ${ }^{\mathrm{a}, \mathrm{c}}$ & 0 & 14 & 14 & 94.9 & 0 & 11 & 11 \\
\hline Columba livia (Rock Dove) & 13 & 0 & 13 & 95.4 & 2 & 0 & 2 \\
\hline Platylophus galericulatus (Crested Jay NT) ${ }^{\mathrm{a}}$ & 1 & 11 & 12 & 95.8 & 1 & 11 & 12 \\
\hline Alophoixus ochraceus (Ochraceous Bulbul) & 1 & 10 & 11 & 96.2 & 1 & 9 & 10 \\
\hline Zosterops palpebrosus (Oriental White-eye) ${ }^{\mathrm{b}}$ & 0 & 11 & 11 & 96.6 & 0 & 6 & 6 \\
\hline Oriolus chinensis (Black-naped Oriole) (c,d $^{\mathrm{c}}$ & 1 & 8 & 9 & 96.9 & 1 & 8 & 9 \\
\hline Estrildidae sp. (Estrildid Finch sp.) & 0 & 6 & 6 & 97.1 & 0 & 3 & 3 \\
\hline Orthotomus sp. (tailorbird sp.) & 0 & 6 & 6 & 97.3 & 0 & 2 & 2 \\
\hline Picidae sp. (woodpecker sp.) ${ }^{\mathrm{d}}$ & 2 & 4 & 6 & 97.5 & 2 & 2 & 4 \\
\hline Garrulax sp. (laughingthrush sp.) & 0 & 5 & 5 & 97.7 & 0 & 5 & 5 \\
\hline Eclectus roratus (Eclectus Parrot) ${ }^{\mathrm{d}}$ & 1 & 3 & 4 & 97.8 & 1 & 1 & 2 \\
\hline Psittacula alexandri (Red-breasted Parakeet NT) & 0 & 4 & 4 & 98 & 0 & 2 & 2 \\
\hline Nectariniidae sp. (sunbird sp.) & 0 & 4 & 4 & 98.1 & 0 & 3 & 3 \\
\hline Aegithina tiphia (Common Iora) & 0 & 3 & 3 & 98.2 & 0 & 3 & 3 \\
\hline Strigiformes sp. (owl sp.) & 0 & 3 & 3 & 98.3 & 0 & 2 & 2 \\
\hline Ixos malaccensis (Streaked Bulbul NT) & 0 & 3 & 3 & 98.4 & 0 & 3 & 3 \\
\hline Chloropsis media (Sumatra Leafbird VU) ${ }^{\mathrm{b}, \mathrm{c}}$ & 0 & 3 & 3 & 98.5 & 0 & 3 & 3 \\
\hline Garrulax leucolophus (White-crested Laughingthrush) & 0 & 3 & 3 & 98.6 & 0 & 3 & 3 \\
\hline Aplonis panayensis (Asian Glossy Starling) & 0 & 2 & 2 & 98.7 & 0 & 2 & 2 \\
\hline Megalaimidae sp. (barbet sp.) & 2 & 0 & 2 & 98.8 & 2 & 0 & 2 \\
\hline Pycnonotus atriceps (Black-headed Bulbul) & 0 & 2 & 2 & 98.8 & 0 & 2 & 2 \\
\hline Garrulax lugubris (Black Laughingthrush) ${ }^{\mathrm{d}}$ & 1 & 1 & 2 & 98.9 & 1 & 1 & 2 \\
\hline Pycnonotidae sp. (bulbul sp.) & 0 & 2 & 2 & 99 & 0 & 1 & 1 \\
\hline Cyornis banyumas (Hill Blue Flycatcher) ${ }^{\mathrm{b}}$ & 2 & 0 & 2 & 99.1 & 2 & 0 & 2 \\
\hline Alcedines sp. (kingfisher sp.) & 0 & 2 & 2 & 99.1 & 0 & 1 & 1 \\
\hline Garrulax rufifrons (Rufous-fronted Laughingthrush CE) ${ }^{\mathrm{a}}$ & 0 & 2 & 2 & 99.2 & 0 & 2 & 2 \\
\hline Pycnonotus squamatus (Scaly-breasted Bulbul NT) ${ }^{\mathrm{d}}$ & 1 & 1 & 2 & 99.3 & 1 & 1 & 2 \\
\hline Unknown (sparrow) & 0 & 2 & 2 & 99.3 & 0 & 1 & 1 \\
\hline Gracupica contra floweri (Asian Pied Starling) ${ }^{\mathrm{a}}$ & 0 & 1 & 1 & 99.4 & 0 & 1 & 1 \\
\hline Dicrurus macrocercus (Black Drongo) & 0 & 1 & 1 & 99.4 & 0 & 1 & 1 \\
\hline Loriculus galgulus (Blue-crowned Hanging Parrot) & 0 & 1 & 1 & 99.4 & 0 & 1 & 1 \\
\hline Cissa chinensis (Common Green Magpie) ${ }^{\mathrm{C}}$ & 1 & 0 & 1 & 99.5 & 1 & 0 & 1 \\
\hline Psilopogon pyrolophus (Fire-tuftet Barbet) & 0 & 1 & 1 & 99.5 & 0 & 1 & 1 \\
\hline Megalaima pulcherrima (Golden-naped Barbet) & 0 & 1 & 1 & 99.5 & 0 & 1 & 1 \\
\hline Lonchura leucogastroides (Javan Munia) & 0 & 1 & 1 & 99.6 & 0 & 1 & 1 \\
\hline Ficedula westermanni (Little Pied Flycatcher) & 0 & 1 & 1 & 99.6 & 0 & 1 & 1 \\
\hline Heterophasia picaoides (Long-tailed Sibia) & 0 & 1 & 1 & 99.6 & 0 & 1 & 1 \\
\hline Rhipidura javanica (Malaysian Pied Fantail) & 0 & 1 & 1 & 99.7 & 0 & 1 & 1 \\
\hline Pericrocotus sp. (minivet sp.) & 0 & 1 & 1 & 99.7 & 0 & 1 & 1 \\
\hline Gracupica contra (Pied Myna) & 1 & 0 & 1 & 99.8 & 1 & 0 & 1 \\
\hline Unknown (quail) & 1 & 0 & 1 & 99.8 & 1 & 0 & 1 \\
\hline Garrulax bicolor (Sumatra Laughingthrush EN) ${ }^{\mathrm{a}, \mathrm{c}}$ & 0 & 1 & 1 & 99.8 & 0 & 1 & 1 \\
\hline Unknown (unknown) & 0 & 1 & 1 & 99.9 & 0 & 1 & 1 \\
\hline Gallicrex cinerea (Watercock) & 0 & 1 & 1 & 99.9 & 0 & 1 & 1 \\
\hline Amaurornis phoenicurus (White-breasted Waterhen) & 0 & 1 & 1 & 99.9 & 0 & 1 & 1 \\
\hline Cacatua sulphurea (Yellow-crested Cockatoo CE) & 0 & 1 & 1 & 100 & 0 & 1 & 1 \\
\hline Serinus mozambicus (Yellow-fronted Canary) & 0 & 1 & 1 & 100 & 0 & 1 & 1 \\
\hline
\end{tabular}

a This species is particularly threatened due to bird pet trade (Eaton et al., 2015 Forktail).

b This species is particularly threatened due to bird pet trade (Asian Songbird Crisis Summit in Singapore, September 2015, www.traffic.org).

c This species is declining in Sumatra due to bird pet trade (Harris et al., 2015 Biological Conservation).

d Both captive-bred and wild-caught birds account for at least $10 \%$ of the individual birds from that species. 
significantly higher proportions of captive-bred birds than expected if even distribution across districts is assumed, whereas two districts (Johor, Selayang) had fewer (Fig. 1). Increasing socio-economic status was correlated with an increasing probability of owning captive-bred birds. Although socio-economic status was not evenly distributed across the sampled Medan districts, it appears to play a role in captive-bred bird ownership even once district is taken into account. The most parsimonious model to explain the demographic difference between owners who had at least one wild-caught bird and those who had only captivebred birds contained just one variable, district (Table 3), with the same districts over- and under-represented in terms of owning exclusively captive-bred birds.

\subsection{Reasons for owning wild-caught versus captive-bred birds}

Among those interviewees who owned a captive-bred bird, the most commonly stated reason for owning it, rather than a wild-caught one, was the lack of an alternative choice (44\%, Fig. $2 \mathrm{~A})$, followed by the reportedly better song of captive-bred birds in comparison to wild-caught ones (20\%). The lower cost and better quality of captive-bred birds were also fairly frequent reasons (10\% each). Owners who did not have any captive-bred birds also said most frequently that it was because of the lack of choice (41\%, Fig. 2B). Interestingly, many owners of wild-caught birds said that their reason for having wild-caught birds was the higher cost of captive-bred birds (25\%) and the perceived worse song of captive-bred birds compared with song of wild-caught birds (20\%), thus contradicting the opinions of those owners of captive-bred birds who cited price and song quality as factors favoring their choice of captivebred birds. (We do not know whether this indicates contradictory opinions about the same bird species, or whether there is broad variation between characteristics of wild-caught and captive-bred birds.) Color, rarity, and dislike for either captive-bred or wild-caught birds did not feature strongly in the most important reasons, contrary to previous observations (Shepherd et al., 2004).

As the lack of alternative choice was the most important reason for owning captive-bred birds as well as for not owning captive-bred birds, we fitted a logistic regression to test if the probability of owning captive-bred birds depends on self-reported access to captive-bred birds. We found that the probability of owning only captive-bred birds increased slightly but significantly with the self-reported ease of access to captive-bred birds ( $p<0.001$, Fig. S1).

\subsection{Case study on Copsychus malabaricus}

We interviewed 307 owners of wild-caught $C$. malabaricus in the second phase of the experiment. Almost two thirds of these owners

Table 2

Ranking of candidate models that describe demographic differences between owners that have captive-bred birds compared to those that only have wild-caught birds, with the most parsimonious model in the first row.

\begin{tabular}{|c|c|c|c|c|c|c|c|c|}
\hline Age & District & Ethnic & SES & df & logLik & AICc & Delta AICc & Weight \\
\hline & + & & + & 12 & -434.87 & 894.15 & 0 & 0.44 \\
\hline \multirow[t]{2}{*}{+} & + & & + & 13 & -434.15 & 894.79 & 0.64 & 0.32 \\
\hline & + & + & + & 14 & -434.45 & 897.47 & 3.32 & 0.08 \\
\hline \multirow[t]{2}{*}{+} & + & + & + & 15 & -433.67 & 897.98 & 3.83 & 0.07 \\
\hline & + & & & 10 & -439.33 & 898.95 & 4.79 & 0.04 \\
\hline \multirow[t]{2}{*}{+} & + & & & 11 & -438.45 & 899.25 & 5.1 & 0.03 \\
\hline & + & + & & 12 & -439.27 & 902.96 & 8.8 & 0.01 \\
\hline+ & + & + & & 13 & -438.36 & 903.22 & 9.06 & 0 \\
\hline \multirow[t]{2}{*}{+} & & & + & 4 & -466.3 & 940.65 & 46.5 & 0 \\
\hline & & & + & 3 & -467.57 & 941.17 & 47.02 & 0 \\
\hline \multirow[t]{2}{*}{+} & & & & 2 & -469 & 942.01 & 47.86 & 0 \\
\hline & & & & 1 & -470.77 & 943.55 & 49.4 & 0 \\
\hline \multirow[t]{2}{*}{+} & & + & + & 6 & -466.25 & 944.61 & 50.46 & 0 \\
\hline & & + & + & 5 & -467.49 & 945.07 & 50.91 & 0 \\
\hline \multirow[t]{2}{*}{+} & & + & & 4 & -468.89 & 945.83 & 51.67 & 0 \\
\hline & & + & & 3 & -470.59 & 947.2 & 53.05 & 0 \\
\hline
\end{tabular}

stated that their reason for not owning a captive-bred $C$. malabaricus was a worse quality of song of captive-bred individuals (Fig. 2C). Being allowed to state more than one reason, $44 \%$ of owners of wildcaught individuals also said that captive-bred C. malabaricus were of poor quality. The third most common reason (38\%) was a lack of choice, referring to having no access to captive-bred C. malabaricus.

In the preliminary playback experiment, 159 owners of wild-caught C. malabaricus were exposed to the two recordings sung by prize-winning captive-bred and wild-caught C. malabaricus. 101 owners (63.5\%) correctly guessed which recording was sung by the wild-caught bird, which is significantly higher than the proportion of correct answers expected by chance $(p<0.001)$. The wild-caught bird's song was ranked slightly, but significantly better than the captive-bred bird song (4.42 vs. 4.02 for wild-caught and captive-bred respectively, $p<0.0001$, Fig. 3).

\section{Discussion}

Wild-caught birds are very popular among bird owners in Medan, Indonesia; $84 \%$ of the 762 bird owners randomly selected for an interview reported that they owned at least one wild-caught bird. Even though captive-bred birds are relatively common (39\% of all birds owned were captive-bred), they almost exclusively belong to a few popular, domesticated species that are not obtainable as wild-caught individuals in Indonesia, such as Agapornis sp., Serinus canaria, and Melopsittacus undulatus. For species that are available both as captivebred and wild-caught individuals, such as Copsychus saularis, Acridotheres tristis, and Copsychus malabaricus, the wild-caught individuals were far more commonly owned (Table 1). Sourcing birds from the wild for the pet trade in Medan is clearly a very common activity, likely leading to huge pressure on wild bird populations (Eaton et al., 2015; Harris et al., 2015).

People who owned wild-caught birds offered three main reasons for doing so (in order of decreasing frequency): a) the lack of choice to purchase captive-bred birds; b) the higher price of captive-bred birds compared with wild-caught individuals; and c) a belief that wild-caught birds have songs superior to captive-bred individuals of the same species. These reasons have to be taken into account when designing conservation interventions to decrease pressure on wild populations, and we elaborate on them below. Fortunately, we did not find that rarity featured among the most important reasons for owning wild-caught rather than captive-bred birds, neither in general, nor with regards to C. malabaricus specifically; the desire to own rare species because of their rarity can prevent successful conservation interventions on behalf of declining species (Alves et al., 2013; Lyons and Natusch, 2013).

\subsection{Lack of choice}

Our findings suggest that a scaled-up captive-breeding program offering substitutes for wild-caught birds in sufficient quantities and at competitive prices could alleviate some of the pressure on wild bird populations in Sumatra. This is because the most frequent reason that owners gave for not owning captive-bred birds is the lack of access to captive-bred birds (Fig. 2). We also found the self-reported ease of access to captive-bred birds to be positively correlated with owning exclusively captive-bred birds (Fig. S1). These two results suggest that the limited availability of captive-bred birds at the Medan bird markets might be an important factor depressing rates of ownership of captive-bred birds, especially in the Medan districts of Johor and Selayang (Fig. 1). The fact that certain districts within Medan are 'hotspots' of ownership of wild-caught birds suggests that captive breeding programs and, potentially, promotional campaigns to encourage the purchase of captive-reared birds should be focused on those districts. However, many interviewees who did own captive-bred birds said they also did so because of the lack of alternative choices. While many of these interviewees may be speaking about species that are not 


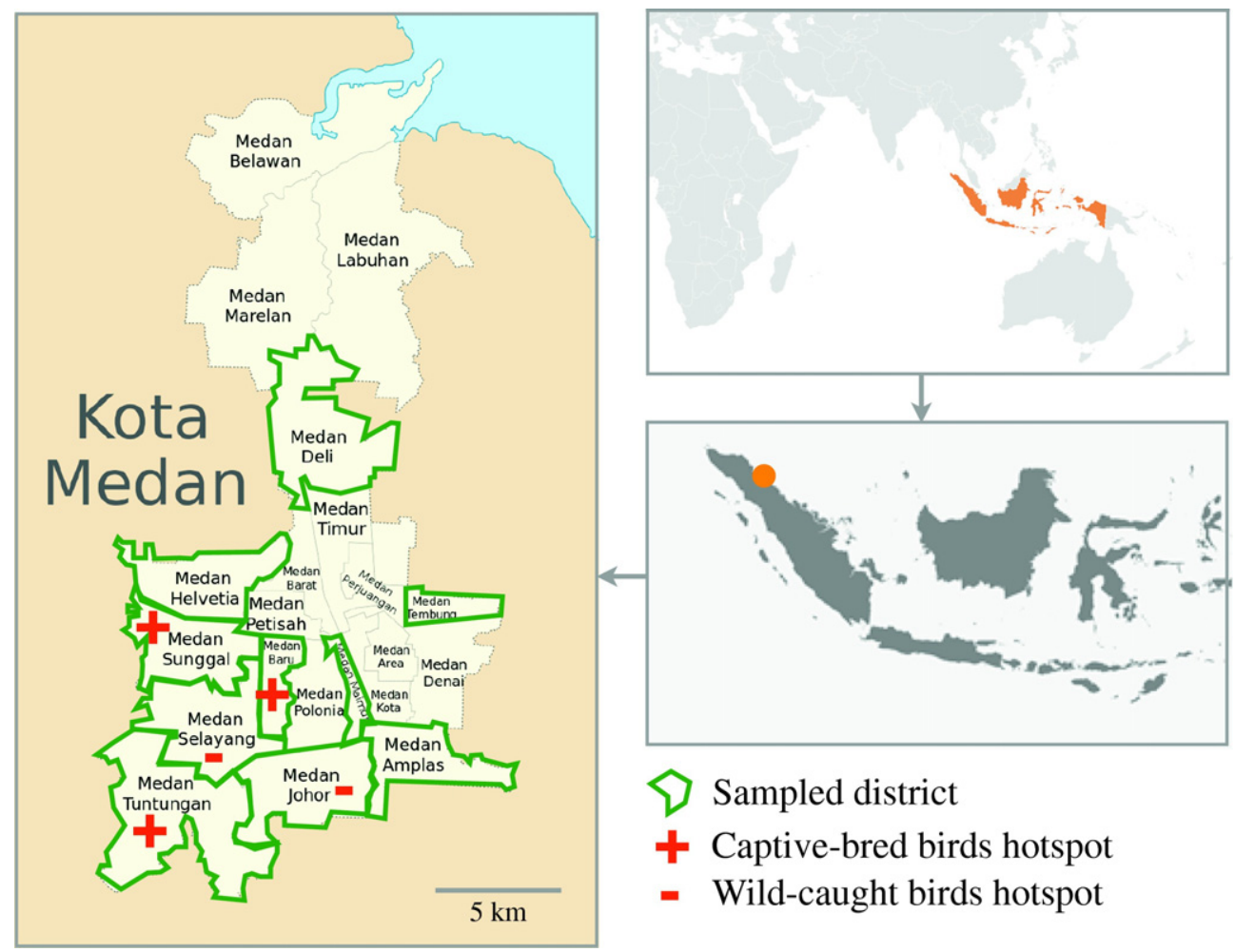

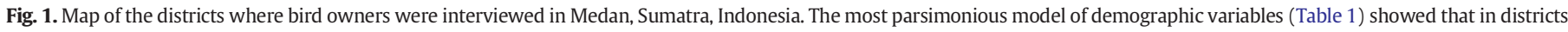

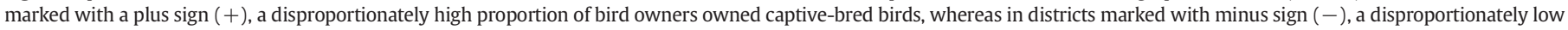
proportion of bird owners had captive-bred birds.

available as wild-caught individuals (e.g. Serinus canaria, Agapornis sp., or Melopsittacus undulatus), this finding nonetheless suggests that owners may switch to wild-caught birds if these were more readily available. Regardless, enforced regulations restricting the sale of wildcaught individuals of overexploited species are also necessary to stem declines (Shepherd, 2006; Eaton et al., 2015).

Captive-breeding programs appear most feasible and might have the biggest impact if focused on three species: Copsychus saularis, $C$. malabaricus, and Chloropsis sonnerati. These species are threatened by the bird trade, they contribute disproportionately to the total number of birds owned, and they are available as captive-bred individuals, albeit at low frequencies. According to our results (Table 1), the availability of these focal species would need to increase about $6-8$ fold if all wildcaught individuals currently owned were replaced with captive-bred

\section{Table 3}

Ranking of candidate models that describe demographic differences between owners that have wild-caught birds compared to those that only have captive-bred birds, with the most parsimonious model in the first row.

\begin{tabular}{|c|c|c|c|c|c|c|c|c|}
\hline Age & District & Ethnic & SES & df & logLik & AICc & deltaAICc & Weight \\
\hline & + & & & 10 & -263.92 & 548.14 & 0 & 0.54 \\
\hline \multirow[t]{3}{*}{+} & + & & & 11 & -263.92 & 550.19 & 2.06 & 0.19 \\
\hline & + & & + & 12 & -263.56 & 551.53 & 3.39 & 0.1 \\
\hline & + & + & & 12 & -263.77 & 551.95 & 3.81 & 0.08 \\
\hline+ & + & & + & 13 & -263.55 & 553.59 & 5.45 & 0.04 \\
\hline \multirow[t]{2}{*}{+} & + & + & & 13 & -263.77 & 554.02 & 5.88 & 0.03 \\
\hline & + & + & + & 14 & -263.42 & 555.4 & 7.26 & 0.01 \\
\hline \multirow[t]{3}{*}{+} & + & + & + & 15 & -263.41 & 557.47 & 9.33 & 0.01 \\
\hline & & + & & 3 & -332.75 & 671.53 & 123.39 & 0 \\
\hline & & + & + & 5 & -331.37 & 672.82 & 124.68 & 0 \\
\hline+ & & + & & 4 & -332.46 & 672.98 & 124.84 & 0 \\
\hline \multirow[t]{3}{*}{+} & & + & + & 6 & -330.91 & 673.94 & 125.8 & 0 \\
\hline & & & & 1 & -336.81 & 675.63 & 127.49 & 0 \\
\hline & & & + & 3 & -335.4 & 676.83 & 128.69 & 0 \\
\hline+ & & & & 2 & -336.6 & 677.22 & 129.09 & 0 \\
\hline+ & & & + & 4 & -335.04 & 678.13 & 129.99 & 0 \\
\hline
\end{tabular}

individuals from the same species in the future, and if we assume that availability would translate directly to ownership (but see Caveats below).

\subsection{Cost of captive-bred birds}

The cost of birds produced in captive breeding programs will likely be critical to determining whether buyers choose captive-bred over wild-caught birds, as the high cost of captive-bred birds was stated as the second most important reason for not having a captive-bred bird by owners of wild-caught birds. Also supporting this result is our finding that captive-bred birds were owned more commonly by people with a higher self-reported socio-economic status, a factor which has been found in other studies to play an important role in captive-bred bird ownership (Jepson et al., 2011; Alves et al., 2013). The higher cost of captive-bred animals can prevent the desired decrease in purchase of wild-caught individuals, such as in the case of farmed porcupines in Vietnam, where, in spite of a large supply of farmed porcupines for meat, restaurants still source almost all their porcupines from the wild, at half the price of farmed animals (Brooks et al., 2010). Perhaps, as captive-breeding operations gain expertise and/or grow larger, the price of captive-bred birds will drop. But if not, price could remain a serious obstacle to reducing the demand for wild-caught birds. For example, in Brazil the cost of captive-bred birds is often ten times higher than the cost of wild-caught birds, preventing a broader uptake (Alves et al., 2013).

\subsection{Quality of song}

Our results suggest that a major hurdle in replacing wild-caught birds on the market with captive-bred ones might be the perceived differences in song quality: The third most common reason for not owning a captive-bred bird was the perceived lower quality of song (Fig. 2B). Interestingly, however, those who did own captive-bred birds also often 

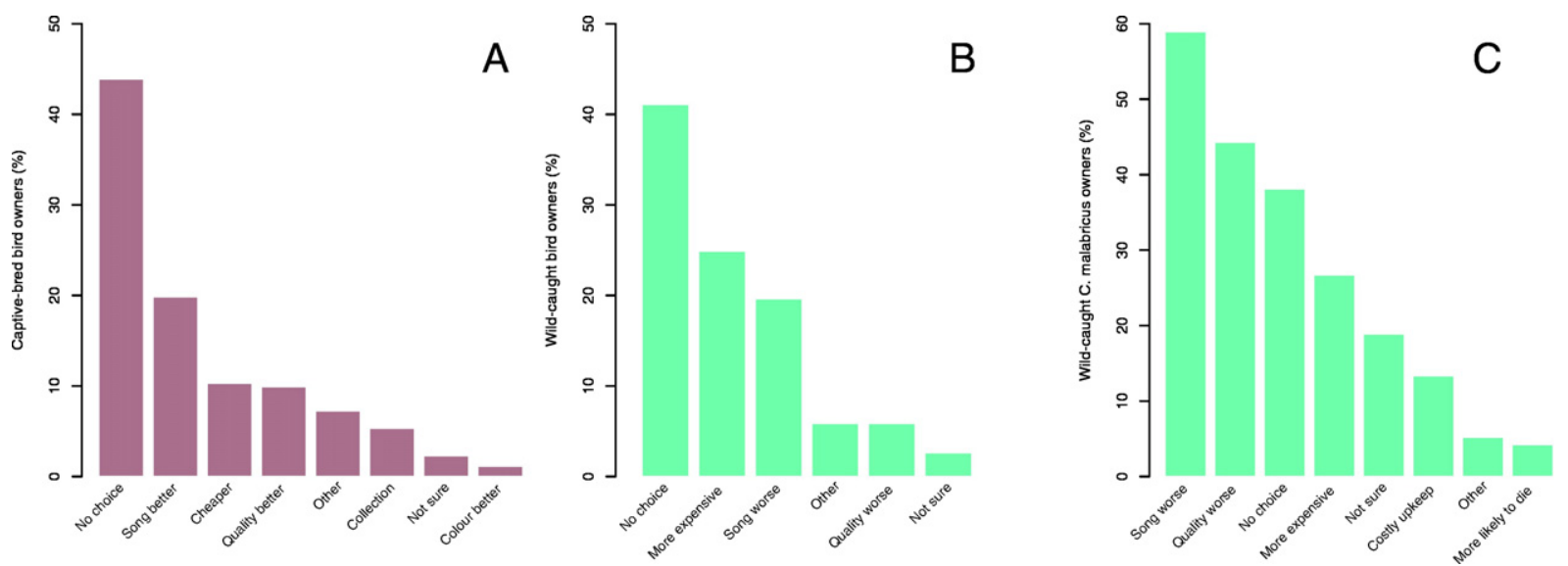

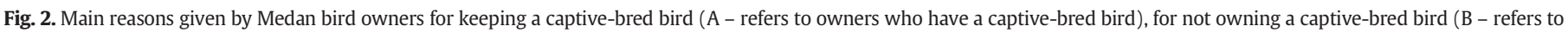
owners who do not have any captive-bred birds), and the reasons given by owners of wild-caught Copsychus malabaricus for not owning a captive-bred individual (C).

stated that they did so because of the better song of captive-bred birds (Fig. 2A). There is therefore a lack of consensus on whether captivebred birds have better or worse songs than wild-caught birds. Even though we do not know the extent to which these results are affected by the particular species the interviewees owned, or by the possibility that owners tend to convince themselves that they had made the best choice with their purchase, through post-purchase rationalization (Mather et al., 2000), it points to a need for further species-by-species investigation, such as the case study on C. malabaricus.

\subsection{Case study}

We have shown for the coveted C. malabaricus that the difference in quality of song might indeed prevent the uptake of captive-bred individuals even if captive-bred birds become readily available. We found that among owners of wild-caught $C$. malabaricus, the perceived better song quality of wild-caught individuals is indeed their most important reason for not owning captive-bred individuals (Fig. 2C). But is the difference in song quality between captive-bred and wild-caught individuals of $C$. malabaricus real or perceived? Could owners be convinced to choose captive-bred individuals as pets if they are exposed to high quality songs sang by captive-bred individuals?

Further research in the form of randomized control trials, and a broader range of recordings of wild-caught and captive-bred birds is needed to ascertain this (we only used one recording of wild-caught and one of captive-bred C. malabaricus), but our preliminary results suggest that whereas the preference for wild-caught bird song seems to be real, captive-bred bird song can be valued almost as highly as wild-bird song. First, in a specific, hand-picked case of two song competition champions, more owners of wild C. malabaricus were indeed able to tell the difference between the captive-bred and the wild-caught individual than would be expected by chance. At the same time, almost one third of owners were not able to guess correctly. Second, the owners of wild-caught $C$. malabaricus ranked the wild-caught champion bird's song slightly but significantly higher than the captive-bred bird song (Fig. 3). Nevertheless, we find it noteworthy and encouraging that the song ranking of the captive-bred champion by the owners of wildcaught $C$. malabaricus was only slightly lower than that of the wildcaught champion. This, together with the simple fact that there exists a captive-bred bird song competition champion that has won many
Phase 1

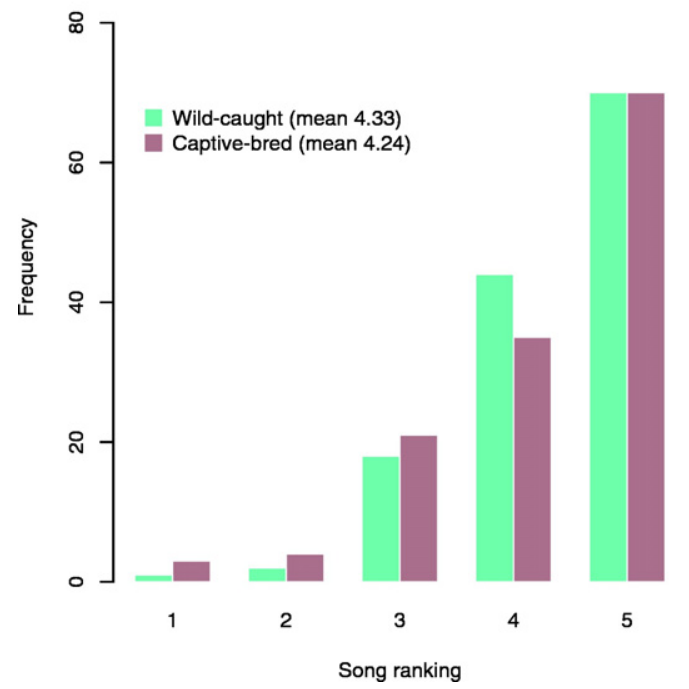

Phase 2

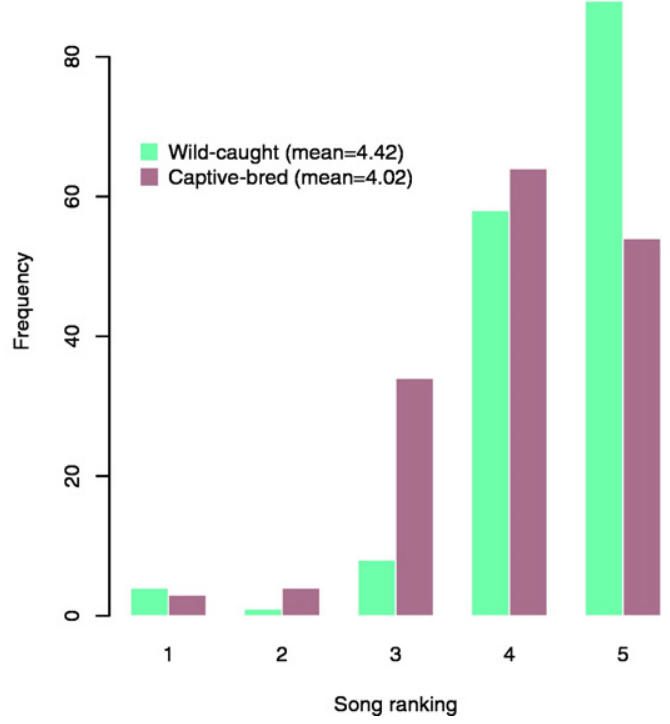

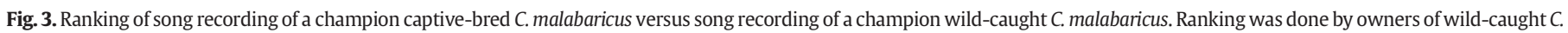
malabaricus as part of a blind test. Owners ranked song as $1=$ below average, $2=$ slightly below average, $3=$ average, $4=$ slightly above average, $5=$ above average. 
prizes, suggests that even captive-bred birds can be highly valued for their song (Jepson et al., 2011).

Previous studies have found that preferences for various characteristics of song competition birds in Indonesia and Taiwan fluctuate and are strongly influenced by fashion (Jepson et al., 2011; Su et al., 2015). This, together with our preliminary results, suggests that it may be more efficient to make owning captive-bred $C$. malabaricus more popular or fashionable, rather than trying to convince bird owners that the songs of captive-bred birds are inherently equal to or better than those of wild-caught birds. One such way might be to establish and promote bird song competition classes restricted to captive-bred C. malabaricus (Jepson et al., 2011). If accompanied by decreasing prices of captivebred $C$. malabaricus, this may be an efficient conservation intervention to reduce the pressure on wild populations of this species.

\subsection{Caveats}

Increasing captive-breeding programs, as well as encouraging song competition categories exclusively for captive-bred birds, are proposed solutions that would require careful monitoring in order to prevent potential perverse outcomes (Bulte and Damania, 2005; Brooks et al., 2010). For example, captive-breeding programs may require the periodic importation of breeding pairs from the wild, such as is the case in the captive breeding farms of $C$. malabaricus in Jakarta (T.M.L. personal observations). In the case of Vietnamese porcupine, caused substantial pressure on wild populations as the breeding of porcupines became more popular, but failed to replace sourcing of porcupines for consumption from the wild (Brooks et al., 2010). Captive-breeding programs provide possibilities for the laundering of wild-sourced animals, especially if there is either a social stigma or a legal restriction on owning wildcaught individuals (Fischer, 2004; Bulte and Damania, 2005; Shepherd et al., 2012; Alves et al., 2013; Robinson et al., 2015). Even if domestic demand for wild-caught birds decreased, over-trapping of birds in the wild may still be a problem because of the important role Indonesia plays in the export of pet birds to other countries, such as Taiwan (Su et al., 2014, 2015). Finally, the prevalence of captive-breeding programs can decrease the stigma of having certain threatened species, which might in turn increase consumer appetite for those species. If captive breeding programs cannot satisfy the demand, this could result in even higher pressure on wild populations (Fischer, 2004; Williams et al., 2014). An important future research question is therefore whether increasing the availability (through breeding programs) of non-native species could ever satisfy the demand for birds native to Indonesia altogether. This would clearly have the advantage of reducing the possibility of laundering certificates; however, it could potentially be problematic in terms of increasing the likelihood of invasive species establishment in places where the species in question is not native (Eaton et al., 2015; Su et al., 2015).

Indeed, market-based approaches to conservation of species endangered by domestic trade, such as commercial captive breeding, need to be researched more extensively to eliminate the possibility of perverse outcomes (Alves et al., 2013). Importantly, captive breeding should be a part of a holistic strategy to address the urgent conservation crisis of bird trade in Indonesia, combined with, among other steps, in situ and ex situ species management, investing in education (which would make bird owners aware of other forms of bird-related hobbies, such as bird watching), and incentivizing trappers to become guides to visiting birdwatchers instead (Alves et al., 2013; Eaton et al., 2015).

\section{Conclusions}

Through a detailed survey of 762 owners, we found that in Medan, Indonesia, owning wild-caught birds remains a widespread practice that has been linked to marked declines of certain species (Harris et al., 2015). We conclude that increasing the availability of captive-bred individuals of popular bird species that are declining in the wild, namely
Copsychus malabaricus, Copsychus saularis, and Chloropsis sonnerati, might help to alleviate pressure on wild populations. Decreasing the cost of captive-bred birds will be important to the uptake in captivebred bird ownership. In the specific case of a popular species in song competitions, $C$. malabaricus, encouraging competition categories exclusively for captive-bred birds might decrease the pressure on the wild populations as well. Our study reinforces the message that the social aspects of wildlife trade need to be carefully examined prior to implementing conservation interventions.

Supplementary data to this article can be found online at http://dx. doi.org/10.1016/j.biocon.2017.03.005.

\section{Acknowledgements}

We thank the team of interviewers in Medan, led by Rudianto Sembiring, and included undergraduate and postgraduate research assistants Azum, Bambang, Dedy, Fivin, Lamberta, Lamhot, Mawan, Ode, Puspita, Rio, Tiwy, and Zebulon. We also thank Nursahara Pasaribu (University of Sumatera Utara), and Bert Harris. We thank the High Meadows Foundation for its support of this work. ZB was supported in part by the Swiss National Science Foundation during this study.

\section{References}

Akaike, H., 1973. Information theory as an extension of the maximum likelihood principle. In: Petrov, B.N., Csaki, F. (Eds.), Second International Symposium on Information Theory. Akademiai Kiado, Budapest, pp. 267-281.

Alves, R.R.N., de F Lima, J.R., Araujo, H.F.P., 2013. The live bird trade in Brazil and its conservation implications: an overview. Bird Conservation International 23, 53-65.

Brooks, E.G.E., Roberton, S.I., Bell, D.J., 2010. The conservation impact of commercial wildlife farming of porcupines in Vietnam. Biol. Conserv. 143:2808-2814. http://dx.doi. org/10.1016/j.biocon.2010.07.030 (Elsevier Ltd.).

Bulte, E.H., Damania, R., 2005. An economic assessment of wildlife farming and conservation. Conserv. Biol. 19, 1222-1233.

Burnham, K.P., Anderson, D.R., 1998. Model Selection and Multimodel Inference. second ed. Springer.

Bush, E.R., Baker, S.E., Macdonald, D.W., 2014. Global trade in exotic pets 2006-2012. Conserv. Biol. 28, 663-676.

Challender, D.W.S., Harrop, S.R., MacMillan, D.C., 2015a. Towards informed and multi-faceted wildlife trade interventions. Global Ecology and Conservation 3, 129-148.

Challender, D.W.S., Harrop, S.R., MacMillan, D.C., 2015b. Understanding markets to conserve trade-threatened species in CITES. Biol. Conserv. 187:249-259 Retrieved from. http://www.sciencedirect.com/science/article/pii/S0006320715001603.

Davis, R.E., Couper, M.P., Janz, N.K., Caldwell, C.H., Resnicow, K., 2010. Interviewer effects in public health surveys. Health Educ. Res. 25, 14-26.

Dutton, A.J., Hepburn, C., Macdonald, D.W., 2011. A stated preference investigation into the chinese demand for farmed vs. wild bear bile. PLOS ONE 6

Eaton, J.A., Shepherd, C.R., Rheindt, F.E., Harris, J.B.C., Van Balen, S.B., Wilcove, D.S., Collar, N.J., 2015. Trade-driven extinctions and near-extinctions of avian taxa in Sundaic Indonesia. Forktail 31, 1-12.

Fischer, C., 2004. The complex interactions of markets for endangered species products J. Environ. Econ. Manag. 48:926-953 Retrieved April 1, 2013, from. http:// linkinghub.elsevier.com/retrieve/pii/S0095069603001426.

Flores-Macias, F., Chappell, L., 2008. Effects of interviewer gender on survey responses: findings from a household survey in Mexico. International Journal of Public Opinion Research 20, 100-110.

Harris, J.B.C., Green, J.M.H., Prawiradilaga, D.M., Giam, X., Giyanto, D., Hikmatullah, C. Putra, A., Wilcove, D.S., 2015. Using market data and expert opinion to identify overexploited species in the wild bird trade. Biol. Conserv. 187, 51-60.

Harris, J.B.C., et al., 2016. Measuring the impact of the pet trade on Indonesian birds. Conserv. Biol. http://dx.doi.org/10.1111/cobi.12729 (in press).

Huddy, L., Billig, J., Bracciodieta, J., Moynihan, P.J., Pugliani, P., 1997. The effect of interviewer gender on the survey response. Polit. Behav. 19.

Jepson, P., Ladle, R.J., 2005. Bird-keeping in Indonesia: conservation impacts and the potential for substitution-based conservation responses. Oryx 39, 442.

Jepson, P., Ladle, R.J., Sujatnika, 2011. Assessing market-based conservation governance approaches: a socio-economic profile of Indonesian markets for wild birds. Oryx 45 482-491.

Lyons, J.a., Natusch, D.J.D., 2013. Effects of consumer preferences for rarity on the harvest of wild populations within a species. Ecol. Econ. 93:278-283 Retrieved from. http:// www.sciencedirect.com/science/article/pii/S0921800913002000.

Mather, M., Shafir, E., Johnson, M.K., 2000. Misremembrance of options past: source monitoring and choice. Psychol. Sci. 11, 132-138.

Oldfield, S., 2003. The Trade in Wildlife: Regulation for Conservation. Earthscan Publications Ltd., London.

Phelps, J., Webb, E.L., 2015. “Invisible” wildlife trades: Southeast Asia's undocumented illegal trade in wild ornamental plants. Biol. Conserv. 186:296-305. http://dx.doi.org/ 10.1016/j.biocon.2015.03.030 (Elsevier Ltd.). 
Phelps, J., Carrasco, L.R., Webb, E.L., 2014. A framework for assessing supply-side wildlife conservation. Conserv. Biol. 28, 244-257.

Regueira, R.F.S., Bernard, E., 2012. Wildlife sinks: quantifying the impact of illegal bird trade in street markets in Brazil. Biol. Conserv. 149:16-22. http://dx.doi.org/10. 1016/j.biocon.2012.02.009 (Elsevier Ltd.).

Robinson, J.G., Redford, K.H., Bennett, E.L., 1999. Wildlife harvest in logged tropical forests. Science 284, 595-596.

Robinson, J.E., Griffiths, R.A., John, F.A.V.St., Roberts, D.L., 2015. Dynamics of the globa trade in live reptiles: shifting trends in production and consequences for sustainability. Biol. Conserv. 184, 42-50.

Shepherd, C.R., 2006. The bird trade in Medan, north Sumatra: an overview. BirdingASIA $5,16-24$.

Shepherd, C.R., Jeet, S., Wich, S.A., 2004. Open Season: An Analysis of the Pet Trade in Medan, Sumatra 1997-2001. Petaling Jaya, Selangor, Malaysia.
Shepherd, C.R., Stengel, C.J., Nijman, V., 2012. The Export and Re-Export of CITES-Listed Birds from the Solomon Islands. TRAFFIC Southeast Asia, Petaling Jaya, Selangor, Malaysia.

Su, S., Cassey, P., Blackburn, T.M., 2014. Patterns of non-randomness in the composition and characteristics of the Taiwanese bird trade. Biol. Invasions 16, 2563-2575.

Su, S., Cassey, P., Vall-Llosera, M., Blackburn, T.M., 2015. Going cheap: determinants of bird price in the Taiwanese pet market. PLoS One 10, e0127482 Retrieved from. http:// journals.plos.org/plosone/article?id=10.1371/journal.pone.0127482.

Williams, S.J., Jones, J.P.G., Annewandter, R., Gibbons, J.M., 2014. Cultivation can increase harvesting pressure on overexploited plant populations. Ecol. Appl. 24, 2050-2062. 